\title{
Pattern of Orbital Diseases at a Tertiary Oculoplastic Center
}

\author{
Mohammad Idris ${ }^{1}$, Hasan Yaqoob², Muhammad Adnan Khan ${ }^{3}$, Adnan Zar ${ }^{4}$, Saifullah ${ }^{5}$ \\ ${ }^{1,2}$ Lady Reading Hospital, Medical Teaching Institute (MTI), Peshawar, ${ }^{2}$ Department of Ophthalmology, North \\ West Teaching Hospital, Peshawar, ${ }^{3}$ Hayatabad Medical Complex, Medical Teaching Hospital, Peshawar, ${ }^{5}$ LRBT \\ Free Eye Hospital, Akora Khattak, KPK
}

\section{Abstract}

Purpose: To determine the causes and frequency of orbital involvement by systemic disorders and non-ocular trauma at a tertiary Oculoplastic centre.

Study Design: Descriptive cross-sectional retrospective study. Ophthalmology unit

Place and Duration of Study: Department of Ophthalmology, Lady Reading Hospital Medical teaching Institute, Peshawar from January 2012 and Dec 2016.

Methods: A total of 45 patients were included in this study. Patients' demographics, clinical cause of orbitopathy and time delay between the problem noticed by the patient and presentation were recorded. Orbitopathy included the presence of corneal and conjunctival changes, optic nerve disorders, proptosis, orbital bone changes and soft tissue swelling of eyelids. The data was analyzed using SPSS software (version 22). The frequency (percentage) and mean \pm standard deviation were reported for categorical variables.

Results: Mean age of the patients was $28.89 \pm 22.02$ years. There were $26(57.8 \%)$ males $19(42.2 \%)$ females. Commonest disorder was Bacterial Infection in 16 (35.6\%) patients followed by Thyroid orbitopathy, which was seen in $14(31.1 \%)$ cases. Other causes included Leukemia, Lymphoma, Retrobulbar Hemorrhage, Neurofibromatosis, Neuroblastoma, Maxillary Osteosarcoma, Teratoma and Fungal Infection. Time delay between presentation of orbital swelling and first noticed by patient was $147.02 \pm 155.18$ weeks in male while in female the time delay was $148.79 \pm 146.47$ weeks.

Conclusion: The commonest inflammation was due to thyroid, commonest infection was bacterial infection and commonest tumor was leukemia. Imaging and proper workup is important to properly treat any orbital disease.

Key Words: Orbit, Ocular trauma, Neuroblastoma, Orbital lymphoma.

How to Cite this Article: Idris M, Yaqoob H, Khan MA, Zar A, Saifullah. Pattern of Orbital Diseases at a Tertiary Oculoplastic Center. Pak J Ophthalmol. 2021, 37 (1): 70-74.

Doi: https://doi.org/10.36351/pjo.v37i1.1154

\section{INTRODUCTION}

Orbit is a well-protected bony area filled with eyeball, soft tissues, nerves and blood vessels. The bony part

Correspondence: Mohammad Idris

Lady Reading Hospital, Medical Teaching Institute (MTI),

Peshawar

Email: idrisdaud80@gmail.com

Received: October 24, 2020

Accepted: November 16, 2020 has four walls, which continue with the skull through various foramen. ${ }^{1}$ This well protected part of the body needs the help of proper work up, notably imaging, for getting relevant important details for the underlying disease process. Many delicate structures are placed within this cavity with well protected mechanisms. There are many ocular and non-ocular disorders which can cause changes in the orbit (proptosis, eyelid odema and conjunctival swelling, etc). ${ }^{2}$

There are many non-ocular systemic conditions with similar presentations for which orbit serves as window through which important and early 
information can be gathered and proper and timely management is possible. ${ }^{3}$

The rationale of this study was to highlight the importance of orbital abnormalities, which might be the first clinical presentation of a systemic disease or non-ocular trauma. Timely referral by physicians to the ophthalmologist and vice versa may help in early intervention. The purpose of the study was to determine the causes and frequency of orbital involvement by systemic disorders and non-ocular trauma at a tertiary Oculoplastic centre.

\section{METHODS}

A descriptive cross sectional study was performed by consecutive sampling of 45 patients who were diagnosed with orbitopathy at the Department of Ophthalmology Lady Reading Hospital Medical Teaching Institute, Peshawar between January 2012 and Dec 2016. Diagnosis was based on clinical features, imaging and necessary work up in lesion with relevant departments. Informed consent was obtained from all patients or their guardians. This study adhered to the tenets of the Declaration of Helsinki and was approved by the institutional review board. Data collected included patient demographics, clinical cause of orbitopathy and time between problem noticed by the patient or guardian and presentation to the ophthalmologist. Orbitopathy included the presence of corneal and conjunctival changes, optic nerve disorders, proptosis, orbital bone changes and soft tissue swelling of eyelids.

The data were analyzed using SPSS software (version 22). The frequency (percentage) and mean \pm standard deviation were reported for categorical variables. Means and proportions were compared using Student's $t$ test and the chi-square test (or Fisher's exact test, if appropriate), respectively. All tests were two-sided, and a $\mathrm{p}$ value $<0.05$ was considered statistically significant.

\section{RESULTS}

Mean age of the patients was $28.89 \pm 22.02$ years. Male were in majority $26(57.8 \%)$ while females were 19 (42.2\%). Commonest disorder was bacterial infection in $16(35.6 \%)$ patients followed by thyroid orbitopathy, which was seen in $14(31.1 \%)$ cases. Other rare but serious causes included leukemia, lymphoma, retrobulbar hemorrhage, neurofibromatosis, neuroblastoma, maxillary osteosarcoma, teratoma and fungal infection involving orbit. Time delay between presentation of orbital swelling and first noticed by patient was $147.02 \pm$ 155.18 weeks in male while in female the time delay was $148.79 \pm 146.47$ SD in weeks which was slightly more (Table 1).

Table 1: Etiology of orbital involvement by different pathologies and patient demographics.

\begin{tabular}{llrc}
\hline & & $\mathbf{N}$ & $\mathbf{\%}$ \\
\hline \multirow{2}{*}{ Age groups } & 0.08-18years & 22 & $48.9 \%$ \\
& 19 and above & 23 & $51.1 \%$ \\
& Male & 26 & $57.8 \%$ \\
& Female & 19 & $42.2 \%$ \\
& Thyroid orbitopathy & 14 & $31.1 \%$ \\
& Bacterial Infection & 16 & $35.6 \%$ \\
& Leukemia & 2 & $4.4 \%$ \\
& Lymphoma & 1 & $2.2 \%$ \\
& Retrobulbar Hemorrhage & 2 & $4.4 \%$ \\
& Neurofibromatosis & 2 & $4.4 \%$ \\
& Brain Tumor & 1 & $2.2 \%$ \\
& Neuroblastoma & 2 & $4.4 \%$ \\
& Maxillary Osteosarcoma & 1 & $2.2 \%$ \\
& Teratoma & 2 & $4.4 \%$ \\
& Fungal Infection & 2 & $4.4 \%$ \\
\hline
\end{tabular}

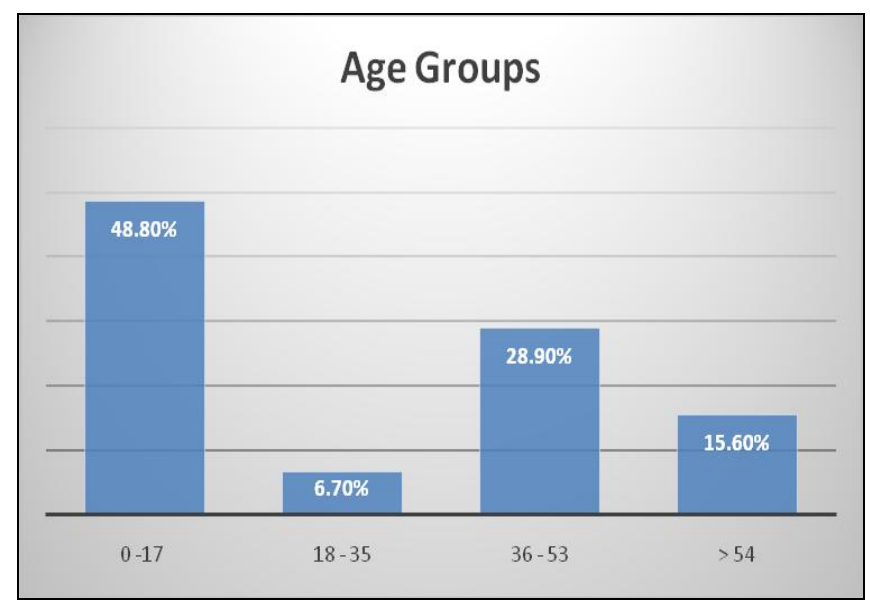

Fig. 1: Distribution according to age groups.

A total of 45 patients were selected. Four age groups were made. For details see figure 1. The most frequent disorder disorders reported or recorded included bacterial infections $(35.6 \%)$ and the $2^{\text {nd }}$ most common was thyroid orbitopathy $(31.1 \%)$. Further details are shown in table 2 and figure 2. 
Table 2: Association of Disorders with Age Groups.

\begin{tabular}{|c|c|c|c|c|c|c|}
\hline \multirow{2}{*}{ Disorder } & \multicolumn{5}{|c|}{ In years } & \multirow{2}{*}{ P Value } \\
\hline & $0-17$ & $18-35$ & $36-53$ & $>54$ & Total & \\
\hline Thyroid orbitopathy & $0 \%$ & $0 \%$ & $22.2 \%$ & $8.9 \%$ & $31.1 \%$ & \multirow{12}{*}{0.001} \\
\hline Bacterial Infection & $26.7 \%$ & $2.2 \%$ & $4.4 \%$ & $2.2 \%$ & $35.6 \%$ & \\
\hline Leukemia & $4.4 \%$ & $.0 \%$ & $.0 \%$ & $.0 \%$ & $4.4 \%$ & \\
\hline Lymphoma & $.0 \%$ & $.0 \%$ & $.0 \%$ & $2.2 \%$ & $2.2 \%$ & \\
\hline Retrobulbar Haemorrhage & $.0 \%$ & $.0 \%$ & $2.2 \%$ & $2.2 \%$ & $4.4 \%$ & \\
\hline Neurofibromatosis & $2.2 \%$ & $2.2 \%$ & $.0 \%$ & $.0 \%$ & $4.4 \%$ & \\
\hline Brain Tumor & $2.2 \%$ & $.0 \%$ & $.0 \%$ & $.0 \%$ & $2.2 \%$ & \\
\hline Neuroblastoma & $4.4 \%$ & $.0 \%$ & $.0 \%$ & $.0 \%$ & $4.4 \%$ & \\
\hline Maxillary Osteosarcoma & $.0 \%$ & $2.2 \%$ & $.0 \%$ & $.0 \%$ & $2.2 \%$ & \\
\hline Teratoma & $4.4 \%$ & $.0 \%$ & $.0 \%$ & $.0 \%$ & $4.4 \%$ & \\
\hline Fungal Infection & $4.4 \%$ & $.0 \%$ & $.0 \%$ & $.0 \%$ & $4.4 \%$ & \\
\hline Total & $48.9 \%$ & $6.7 \%$ & $28.9 \%$ & $15.6 \%$ & $100.0 \%$ & \\
\hline
\end{tabular}

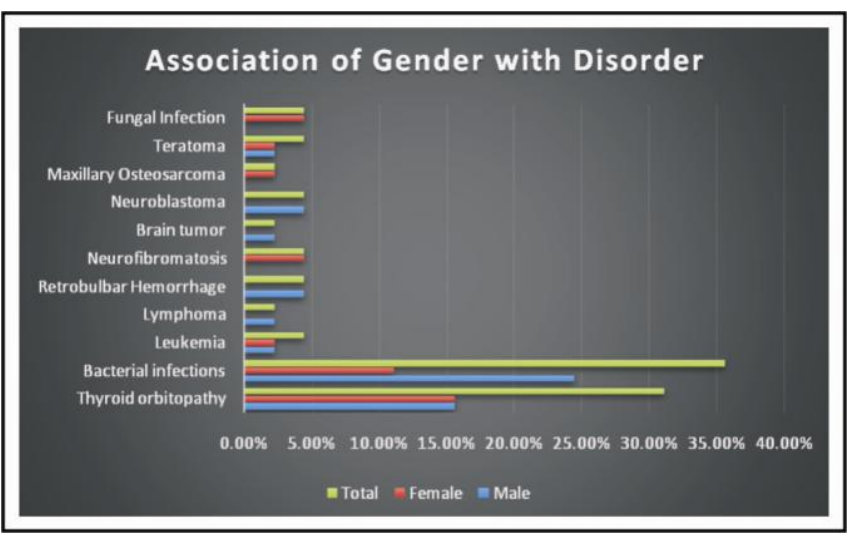

Fig. 2: Association of gender with disorders.

\section{DISCUSSION}

Orbit is involved in many important non ocular conditions which include infections, inflammations, tumors and trauma which shows the importance of all necessary workup for any patient with such abnormality in orbit. ${ }^{4}$ According to the present study, based on our experience of more than 10 years dealing with orbital diseases at our centre, the non ophthalmic diseases which cause changes in the orbit are broadly classified as infective, inflammatory, neoplastic and traumatic.

Thyroid eye disease was the most common cause of orbital disease in our study which is supported by the previous researchers., ${ }^{5,7}$ Thyroid eye disease includes eyelid edema, conjunctival chemosis, proptosis, eyelid retraction and optic nerve compression. Therefore, proper detection and management by ophthalmologist as well as the endocrinologist and other related specialties are important to prevent its complications. ${ }^{8}$ According to
Ackuaku-Dogbe et al, it is common in middle aged females with more than $80 \%$ under the age 50 years. ${ }^{9}$ However, more severe disease is encountered in males which was also seen in our study. ${ }^{10}$

Infections involving orbital region both ocular and systemic are also quite common. The common causes of orbital cellulitis include infections of surrounding areas particularly sinuses, dental area and nose. ${ }^{11,12}$ Immune compromised individuals are mostly infected by the fungi. ${ }^{13}$ According to our study, sinusitis was the most common cause of orbital cellulitis which is in accordance with literature. ${ }^{14}$ Orbital cellulitis as a complication of sinusitis is seen in both genders equally and more common in young children. ${ }^{15}$ These findings were also seen in our study.

Variety of common and rare Tumors also cause different changes in the orbit which range from mild swelling to a large proptosis. One of the common tumors which involve orbit is lymphoma. ${ }^{16}$ Leukemia was seen in one patient which is extremely rare as a cause of proptosis. ${ }^{17}$ Rare tumors of orbit include Orbital teratoma. ${ }^{18}$ Other tumors include maxillary tumor invading the orbit, brain tumors and neuroblastoma. ${ }^{19,20,21}$ All the above mentioned tumors were seen in comparatively least frequency in our study.

According to our results, neurofibromatosis and leukemia were the most common ones. When Neurofibromatosis involves orbit it may cause globe destruction and huge proptosis. It was also evident from our study. ${ }^{22}$

Trauma is common in our region. The common cause of proptosis due to non-ocular trauma was retrobulbar hemorrhage, which is a rare complication 
of non-ocular trauma. The need for early detection through imaging and proper and timely workup is vision saving. Delay in diagnosis can result in optic nerve damage due to compression and ischemia. ${ }^{23,24}$ Untreated or unrecognized cases may result in permanent visual loss within 90-120 minutes. ${ }^{25}$ Therefore immediate management and most importantly recoding of visual acuity at trauma room with proper referral to ophthalmologist and long follow-up is recommended to save vision.

Limitations of this study were descriptive crosssectional design and vascular lesions like fistulas, vascular tumors and AV malformations were not included.

\section{CONCLUSION}

Orbit serves as an important window to both local and systemic diseases, which includes inflammation, infection and tumors and trauma. The commonest inflammation was due to thyroid, commonest infection was bacterial orbital cellulitis and commonest tumor was leukemia. Imaging and proper workup is important to properly treat any orbital disease. Majority of our patients presented at late and advanced stage.

\section{Ethical Approval}

The study was approved by the Institutional review board/ Ethical review board. (3273)

\section{Conflict of Interest}

Authors declared no conflict of interest.

\section{REFERENCES}

1. Felding UNA. Blowout fractures - Clinic, imaging and applied anatomy of the orbit. Dan Med J. 2018; 65 (3): B5459.

2. Nguyen VD, Singh AK, Altmeyer WB, Tantiwongkosi B. Demystifying Orbital Emergencies: A Pictorial Review. Radiographic. 2017; 37 (3): 947962.

3. Mc Nab AA. The 2017 Doyne Lecture: the orbit as a window to systemic disease. Eye (Lond). 2018; 32 (2): 248-261.

4. Abad S, Héran F, Terrada C, Sène D, Trad S, Saadoun D, et al. Orbitopathies inflammatories. Que doit savoir l'interniste? (Management of orbital inflammation in internal medicine. Proposal for a diagnostic work-up). Rev Med Interne. 2018; 39 (9): 746-754.
5. Wang Y, Tooley AA, Mehta VJ, Garrity JA, Harrison AR, Mettu P. Thyroid Orbitopathy. Int Ophthalmol Clin. 2018; 58 (2): 137-179.

6. Drui D, Fediaevski DPL, Clermont C, Daumerie C. Graves' orbitopathy: Diagnosis and treatment. Ann Endocrinol (Paris). 2018; 79 (6): 656-664.

7. Shi TT, Hua L, Wang H, Xin Z. The Potential Link between Gut Microbiota and Serum TRAb in Chinese Patients with Severe and Active Graves' Orbitopathy. Int J Endocrinol. 2019; 2019: 9736968.

8. Drui D, Du-Pasquier FL, Clermont VC, Daumerie C. Graves' orbitopathy: Diagnosis and treatment. Ann Endocrinol (Paris). 2018; 79 (6): 656-664.

9. Ackuaku-Dogbe EM, Akpalu J, Abaidoo B. Epidemiology and Clinical Features of Thyroidassociated Orbitopathy in Accra. Middle East Afr J Ophthalmol. 2017; 24 (4): 183-189.

10. Gharib S, Moazezi Z, Bayani MA. Prevalence and severity of ocular involvement in Graves' disease according to sex and age: A clinical study from Babol, Iran. Caspian J Intern Med. 2018; 9 (2): 178-183.

11. Kinis V, Ozbay M, Bakir S, Ediz Y, Ramazan G, Mehmet A, et al. Management of orbital complications of sinusitis in pediatric patients. J Craniofac Surg. 2013; 24 (5): 1706-1710.

12. de Assis-Costa, Santos GS, Maciel J, Sonoda CK, de Melo WM. Odontogenic infection causing orbital cellulitis in a pediatric patient. J Craniofac Surg. 2013; 24 (5): e526-9.

13. Nasa M, Sharma Z, Lipi L, Sud R. Gastric Angioinvasive Mucormycosis in Immunocompetent Adult, A Rare Occurrence. J Assoc Physicians India. 2017; 65 (12): 103-104.

14. Wong SJ, Levi J. Management of pediatric orbital cellulitis: A systematic review. Int J Pediatr Otorhinolaryngol. 2018; 110: 123-129.

15. Tsirouki T, Dastiridou AI, Ibánez Flores N, Cerpa JC, Moschos MM, Brazitikos P, et al. Orbital cellulitis. Surv Ophthalmol. 2018; 63 (4): 534-553.

16. Olsen TG, Heegaard S. Orbital lymphoma. Surv Ophthalmol. 2019; 64 (1): 45-66.

17. Zhu T, Xi XY, Dong HJ. Isolated myeloid sarcoma in the pancreas and orbit: A case report and review of literature. World J Clin Cases, 2018; 6 (11): 477-482.

18. Barreau G, Mounayer C, Bédu A, Pommepuy I, Robert PY. A newborn saved by embolisation and surgery of a giant teratoma of the orbit. J Fr Ophtalmol. 2017; 40 (4): e137-e139.

19. Mici E, Belli E. Fibrous Dysplasia: A Complex Maxillary Reconstruction. J Craniofac Surg. 2018; 29 (7): e660-e661.

20. Hayashi S, Kurihara H, Hirato J, Sasaki T. Solitary fibrous tumor of the orbit with extraorbital extension: case report. Neurosurgery, 2001; 49 (5): 1241-1245. 
21. Borni M, Kammoun B, Kolsi F, Boudawara MZ. L'esthésioneuroblastome pédiatrique: une lésion maligne exceptionnelle (à propos d'un cas et revue de la littérature) [Pediatric esthesioneuroblastoma: an exceptional malignant lesion (a case study and literature review)]. Pan Afr Med J. 2018; 31: 144.

22. Lafford GH, Eccles SJ, Haq J, Orban N. Sight preserving orbital decompression: a novel multidisciplinary approach to managing severe proptosis in neurofibromatosis type 2. BMJ Case Rep. 2017; 2017: bcr2017221462.

23. Johnson D, Schweitzer K, Sharma S. Answer: Can you identify this condition? Can Fam Physician, 2009; 55 (6): 607.

24. Griffin AS, Hoang JK, Malinzak MD. CT and MRI of the Orbit. Int Ophthalmol Clin. 2018; 58 (2): 25-59.

25. Pamukcu C, Odabaşı M. Acute retrobulbar haemorrhage: An ophthalmologic emergency for the emergency physician. Ulus Travma Acil Cerrahi Derg. 2015; 21 (4): 309-314.

\section{Authors' Designation and contribution}

Mohammad Idris; Assistant Professor: Concepts, Design, Literature search, Data acquisition, Data analysis, Manuscript preparation, Manuscript editing, Manuscript review.

Hasan Yaqoob; Associate Professor: Concepts, Design, Literature search, Data acquisition, Manuscript preparation, Manuscript editing.

Muhammad Adnan Khan; Vitreo retina fellow: Literature search, Data acquisition, analysis, Manuscript preparation, Manuscript editing.

Adnan Zar; SPR: Literature search, Data acquisition.

Saifullah; Associate Professor: Data analysis, Manuscript review. 